\title{
Varying Capacities for Replication of Rat Adipocyte Precursor Clones and Adipose Tissue Growth
}

\author{
H. Wang, J. L. Kirkland, and C. H. Hollenberg \\ Department of Medicine, Institute of Medical Science, and Banting and Best Diabetes Centre, University of Toronto, \\ Toronto, Ontario, Canada M5G 2 C4
}

\begin{abstract}
Rat adipocyte precursor populations contain clones varying in capacity for replication. In this study we explored factors controlling the frequency of clones of varying replicative capacities (clonal composition). We also explored the relationship between this frequency and fat depot growth.

In perirenal and epididymal depots clonal composition was identical bilaterally; perirenal depots contained more extensively replicating clones. Although there were large interanimal differences in clonal composition, variation between animals was always in the same direction for both depots. Clonal composition was unaffected by undernutrition while with animal growth the frequency of the most extensively replicating clones was reduced. Differentiation of precursors occurred in all clones, while differentiation did not occur in skin fibroblasts cloned under identical conditions. Clonal composition and mature fat cell number were related in that fat cell numbers were identical bilaterally in both depots and increased more extensively with growth in perirenal than epididymal tissue.

We conclude (a) that clonal composition of adipocyte precursor populations is regulated genetically and by age, $(b)$ that this composition determines, at least in part, the capacity for adipose depot growth.
\end{abstract}

\section{Introduction}

Growth of adipose tissue is dependent both upon deposition of lipid in existing mature fat cells and the production and filling of new fat cells. The steps involved in the expansion of mature fat cells have been elucidated in some detail. Less is known about the factors regulating the formation of new fat cells and about the quantitative importance of this process at different ages and under varying nutritional and hormonal circumstances. However, studies based on techniques as diverse as counting of fat cells, in vivo incorporation of tritiated thymidine into adipocyte precursors and cell culture of primordial fat cells have produced sufficiently consistent data to allow a general description of the process. It is apparent that while the capacity for new fat cell formation exists throughout life, even into senescence (1), production of fat cells may be more rapid

Address reprint requests to Dr. Hollenberg, Banting and Best Diabetes Centre, 3 CCRW 845, Toronto General Hospital, 200 Elizabeth Street, Toronto, Ontario M5G 2C4.

Received for publication 15 April 1987 and in revised form $8 \mathrm{No}$ vember 1988 .

J. Clin. Invest.

(c) The American Society for Clinical Investigation, Inc.

$0021-9738 / 89 / 05 / 1741 / 06 \$ 2.00$

Volume 83, May 1989, 1741-1746 early in life and at puberty $(2,3)$. While new fat cell formation is reduced by fasting, insulin deficiency and hypophysectomy (4), adipocyte precursor replication is accelerated by several novel pituitary peptides (5) and new fat cell formation is particularly increased by some function associated with massive obesity $(6,7)$. There are marked regional differences in capacity for development of new adipocytes. For example, lipectomy and/or high fat feeding results in greater increases in fat cell number in some depots than in others $(8,9)$.

In an attempt to understand more completely the regulation of fat cell production and its contribution to adipose tissue growth, we have studied the behavior of rat adipocyte precursors in cell culture. In these studies we observed cells generations after removal from the animal and presumably free of persisting in vivo influences. These studies have shown that adipocyte precursor populations derived from either the perirenal or epididymal regions of the rat are polyclonal with respect to capacity for replication and that perirenal populations contain a higher frequency of extensively replicating clones $(10,11)$. This study was designed to extend these observations by exploring factors that might regulate the content within adipocyte precursor populations of clones of varying replicative capacities (clonal composition). We have also studied the relation between the frequency of clones that replicate extensively and the capacity of the parent fat depots for new fat cell formation. We have observed that the regional regulation of clonal composition is probably exerted by genetic factors, and that some function associated with animal growth affects clonal composition of the two depots studied. Finally, we have noted that this composition regulates, in part, the capacity of fat depots to grow through hyperplasia.

\section{Methods}

Animals. Male Sprague-Dawley rats (Charles River Breeding Laboratories Canada Inc., St. Constant, Quebec, Canada) were kept in airconditioned $\left(20-23^{\circ} \mathrm{C}\right)$ quarters with a 12-h light and dark cycle. The animals were housed in pairs for 2-5 $d$ before experiments and were fed with rat Purina Chow (Ralston Purina Co., St. Louis, MO) ad lib. In experiments to study the effect of undernutrition, animals were housed individually and given half their normal daily food intake (i.e., $10 \mathrm{~g}$ rat chow per $\mathrm{d}$ instead of $20 \mathrm{~g}$ per d). In the latter experiments, ad lib.-fed control animals were also housed individually. The initial weight of the animals was in the 70-500-g range depending on the experimental protocol that was used.

Culture and cloning of adipocyte precursors. Fat pads were removed from the animals, weighed, and minced under sterile conditions. The minced tissue was digested in HBSS containing collagenase $1.0 \mathrm{mg} / \mathrm{ml}$ (Type I; Sigma Chemical Co., St. Louis, MO) at pH 7.4 for $45 \mathrm{~min}$ at $37^{\circ} \mathrm{C}$. The resultant cell suspension was centrifuged at $800 \mathrm{~g}$ for 10 min. The sedimented pellet was resuspended in alpha minimal essential medium (MEM) containing $2.2 \mathrm{~g} \mathrm{NaHCO}_{3} /$ liter, 10\% FCS, 100 $\mathrm{U} / \mathrm{ml}$ penicillin, and $100 \mu \mathrm{g} / \mathrm{ml}$ streptomycin (all components from Gibco Laboratories, Grand Island, NY) and plated in 100-mm Petri 
dishes. After $12 \mathrm{~h}$, the nonadherent cells were removed by repeated washings with HBSS. The adherent cells were used as the source of cells in all of the following experiments and are referred to subsequently as adipocyte precursors. Previous studies have demonstrated that replication of the cells does not occur during the $12 \mathrm{~h}$ after plating (10). The adherent cells were detached with a $1-\mathrm{mg} / \mathrm{ml}$ trypsin- $-0.2 \mathrm{mg} / \mathrm{ml} \mathrm{Na}$ EDTA solution, were diluted with fresh $\alpha \mathrm{MEM}$, and were plated in 10 plates at a density of 400 cells $/ 960$ wells ( 96 wells/plate, $0.28 \mathrm{~cm}^{2} /$ well $0.2 \mathrm{ml}$ medium/well, Linbro Scientific Co., Dublin, VA). To assess replicative potential of the clones, cells were kept for $14 \mathrm{~d}$ with fresh $\alpha$ MEM being added $7 \mathrm{~d}$ after plating. After $14 \mathrm{~d}$, the medium was decanted and the cell number of each colony was determined. In the case of large colonies, cells were detached with the trypsin- $\mathrm{Na}_{2}$ EDTA solution and were counted with a hemocytometer. In the case of the smaller colonies, cell numbers were determined by cell counting using a microfilm projector with the aid of a grid after staining with $10 \%$ Giemsa. Colony size was expressed as a logarithm to the base two of cell number in order to reflect the number of population doublings. In each experiment the frequencies of colonies of size $\log _{2} 0$ to $\log _{2} 16$ were expressed as a percentage of the total number of colonies formed. In most of the Tables, colonies of sizes $\log _{2} 0$ to 9 are grouped as are colonies of sizes $\log _{2} 10$ to 12 and $\log _{2} 13$ to 16 . This method of presentation allows ready comprehension of data derived from precursors of very variable replicative capacities and groups these precursors into those with low, intermediate, and high replicative capacities. In some instances, in order to highlight the frequency of the most extensively replicating clones, the frequency of the largest colonies is presented separately.

Differentiation of adipocyte precursors. The capacity of adipocyte precursors to differentiate was studied by growing cells in $\alpha M E M$ with $10 \%$ FCS for $7 \mathrm{~d}$, after which an enriched growth medium was added for another $14 \mathrm{~d}$. The enriched medium contained glucose $25 \mathrm{mM}$, insulin $10 \mu \mathrm{g} / \mathrm{ml}$ (Sigma Chemical Co.), 20\% Nuserum (Collaborative Research, Lexington, MA), $100 \mathrm{U} / \mathrm{ml}$ penicillin, $100 \mu \mathrm{g} / \mathrm{ml}$ streptomycin, and $5 \mathrm{mg} / 100 \mathrm{ml}$ Liposyn (final) (Abbott Laboratories, Montreal, Quebec) in $\alpha$ MEM. Rat skin fibroblasts were cultured under identical conditions.

Determination of fat cell size and number. The size and number of adipocytes in adipose depots were determined by a modification of the method of Di Girolamo (12). After collagenase digestion of the fat pads, an aliquot of the floating fat cells was transferred to a siliconized glass slide. After staining with trypan blue, cells were examined with a microscope fitted with an eyepiece micrometer disk. The free fat cells were distinguished from other cells and fat droplets by presence of cytoplasm and a nucleus and by their spherical shape. In each experiment the diameters of 300 to 400 fat cells were determined by focusing on their broadest widths. From this, the mean cell diameter was calculated. The average fat cell lipid content was estimated by multiplying the mean cell diameter by the density of triolein $(0.915)$. The lipid content of the depot was determined gravimetrically following lipid extraction of the depot by the method of Folch (13). The number of fat cells per pad was estimated by dividing the total lipid content of the tissue by mean fat cell lipid content.

Statistical methods. Results are expressed as means \pm SEM. Chisquare, Student's $t$ and analysis of variance tests (14) were used as indicated in the text and legends.

\section{Results}

Characterization of adipocyte precursors. In each phase of this study, the clonal composition of adipocyte precursor populations was determined by noting, after a period of growth, the frequency of colonies of various sizes. Obviously this approach assumed that each colony was derived from a single precursor and that all cells forming colonies were, in fact, adipocyte precursors. The initial experiments were designed to test these assumptions.
To establish the unicellular origin of each colony, perirenal precursors were plated at varying densities and, after 2 wk of cell culture, a count made of the number of colonies of all sizes resulting from each density of plating. As shown in Fig. 1, a linear relationship between plating density and colony number was observed. This relationship confirms that each colony was, in fact, derived from a single cell.

To establish the adipocyte nature of the colony-forming cells, precursors derived from epididymal and perirenal depots of $170-\mathrm{g}$ rats were exposed to enriched medium during the final $14 \mathrm{~d}$ of a $21-\mathrm{d}$ growth period. Rat skin fibroblasts were treated similarly. 502 of 503 colonies derived from precursors contained cells with doubly refractile inclusions visible by phase contrast microscopy. The lipid character of these droplets was confirmed by Oil Red O staining. None of the 182 fibroblast colonies contained such lipid inclusions. These results established that virtually all cells isolated from fat depots that had the capacity to form colonies also had the capacity for adipocyte differentiation.

Regional variation in clonal composition. Our earlier studies had demonstrated that the adipocyte precursor population derived from perirenal fat contains a greater proportion of extensively replicating clones than the population derived from epididymal tissue (10). In these studies, perirenal and epididymal tissues were removed from different groups of animals and, in each experiment, tissues from the right and left sides were pooled. In the present study comparisons were made of the colony size distributions of perirenal and epididymal tissues derived from the same animal. Additionally, a comparison was made between the colony size distributions of precursors derived from the right and from the left pads in each region. These experiments were done with three $155 \pm 12$ $\mathrm{g}$ rats and in each instance all cells derived from a single animal were cultured simultaneously. The three studies produced the same results and the data from one study are shown in Table I. As had been previously observed using separate

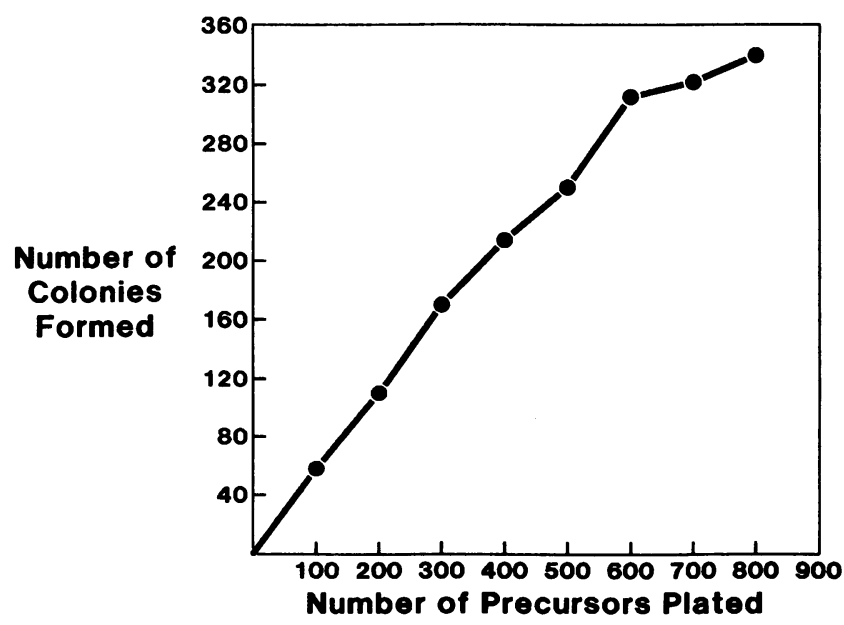

Figure 1. Relation between plating density and colony formation. Perirenal precursors from a single $265 \mathrm{~g}$ rat were plated at eight different densities varying from 100 to 800 cells per 960 wells. After 2 wk of culture a count was made of the number of colonies of all sizes that were produced by the precursors plated at each density. Each point represents the number of colonies resulting from plating at each density. Mean cloning efficiency was $52 \pm 1 \%$. 
Table I. Colony Size Distribution of Adipocyte Precursors from Right and Left Sides of Perirenal and Epididymal Depots

\begin{tabular}{|c|c|c|c|c|}
\hline \multirow[b]{3}{*}{ Colony size } & \multicolumn{4}{|c|}{ Percent distribution of colony size } \\
\hline & \multicolumn{2}{|c|}{ Perirenal } & \multicolumn{2}{|c|}{ Epididymal } \\
\hline & Rt & Lt & Rt & $\mathrm{Lt}$ \\
\hline \multicolumn{5}{|c|}{$\log _{2}$ cell number } \\
\hline $0-9$ & 40 & 41 & 60 & 64 \\
\hline $10-12$ & 36 & 40 & 31 & 29 \\
\hline $13-16$ & 24 & 20 & 9 & 7 \\
\hline
\end{tabular}

Tissues were removed from a single $143-\mathrm{g}$ rat and all precursors were cultured simultaneously.

groups of animals (10), in this internally controlled experiment perirenal tissue contained many more extensively replicating precursor clones than epididymal fat. Further, within each region, the clonal composition of the precursor populations was identical bilaterally. These data establish that clonal composition of adipocyte precursor populations is determined, at least in part, by the region in which the fat tissue resides. The identity of clonal composition bilaterally suggests that regional regulation of clonal composition is likely a function of the embryological origin of the specific depot and hence might be genetically determined.

Interanimal variation in clonal composition. The next experiments were designed to determine whether the frequencies of various adipocyte precursor clones derived from a depot were constant or varied among animals. In this study, perirenal and epididymal adipose tissues were removed from six 170 -g rats. Perirenal and epididymal precursors derived from each rat were cultured separately. All cells derived from rats 1 and 2 were cultured simultaneously as were cells from rats 3 and 4 and rats 5 and 6 . The data are shown in Table II.

As indicated in this Table and as observed repeatedly during our entire study, there was marked interanimal variation in colony size distribution in both depots. Since this variation was evident when precursors from different animals were cultured simultaneously and under identical conditions, the variation cannot be attributed to differences in culture technique and must represent a real biological difference between ani-

Table II. Interanimal Variation in Colony Size Distribution of Adipocyte Precursors of Perirenal (P) and Epididymal (E) Origin

\begin{tabular}{|c|c|c|c|c|c|c|c|c|c|c|c|c|}
\hline \multirow[b]{3}{*}{ Colony size } & \multicolumn{12}{|c|}{ Percent distribution of colony size } \\
\hline & \multicolumn{2}{|c|}{1} & \multicolumn{2}{|c|}{2} & \multicolumn{2}{|c|}{3} & \multicolumn{2}{|c|}{4} & \multicolumn{2}{|c|}{5} & \multicolumn{2}{|c|}{6} \\
\hline & $\mathbf{P}$ & $\mathbf{E}$ & $\mathbf{P}$ & $\mathbf{E}$ & $\mathbf{P}$ & $\mathrm{E}$ & $\mathbf{P}$ & $\mathrm{E}$ & $\mathbf{P}$ & $\mathbf{E}$ & $\mathbf{P}$ & $\mathbf{E}$ \\
\hline \multicolumn{13}{|c|}{$\log _{2}$ cell number } \\
\hline $0-9$ & 27 & 25 & 48 & 49 & 46 & 70 & 48 & 70 & 32 & 43 & 47 & 69 \\
\hline $10-12$ & 12 & 37 & 17 & 32 & 21 & 25 & 29 & 27 & 23 & 33 & 22 & 25 \\
\hline $13-16$ & 61 & 38 & 35 & 19 & 33 & 5 & 23 & 4 & 45 & 24 & 31 & 6 \\
\hline
\end{tabular}

Tissues were removed from six animals varying in weight from 160 to $170 \mathrm{~g}$. mals. Further, it was also apparent that the difference between animals in the frequency of extensively replicating clones was in the same direction for both depots. This congruency in behavior of the two depots became more obvious when the frequencies of the most extensively replicating clones of the two depots were compared using data derived from all studies of $170-\mathrm{g}$ rats in which epididymal and perirenal precursors were cultured simultaneously. In Fig. 2 the sum of the frequencies of colonies size $\log _{2} 13,14,15$, and 16 of perirenal origin was plotted against the corresponding frequency derived from epididymal cells; each point represents a single animal. The linear relationship between the frequencies of extensively replicating clones derived from the two sites suggests that the clonal composition of adipocyte precursors is regulated not just regionally but also by factors that can affect and produce congruent changes in both depots. The next studies were designed to explore the existence of such influences.

Effect of caloric restriction on clonal composition. Previous in vivo studies have demonstrated that fasting retards formation of new fat cells and empties, but does not destroy mature fat cells (4). Hence it was reasonable to explore the possibility that variations in nutrition might exert a general and persisting influence on the frequency of various precursor clones in a variety of adipose beds. In these studies, one perirenal or epididymal fat pad was removed from each of two groups of $170-\mathrm{g}$ rats at 0 time. One group was then fed a normal ration, the other $50 \%$ of a normal ration for 3 wk after which the contralateral pad was removed. The normally fed group gained an average of $138 \mathrm{~g}$ during the three week interval, the calorie restricted group $10 \mathrm{~g}$. The colony size distributions of the pads removed at 0 and $21 \mathrm{~d}$ were determined and compared. The data are shown in Table III.

It is apparent that the colony size distributions of both perirenal and epididymal precursors were remarkably constant over the 3-wk interval in both groups and that undernutrition, at least in 8-wk-old rats, had no discernible effect on the frequency of the various precursor clones. Hence it is very unlikely that interanimal variations in nutritional intake were responsible for the marked interanimal variation that was noted in the clonal composition of adipocyte precursor populations.

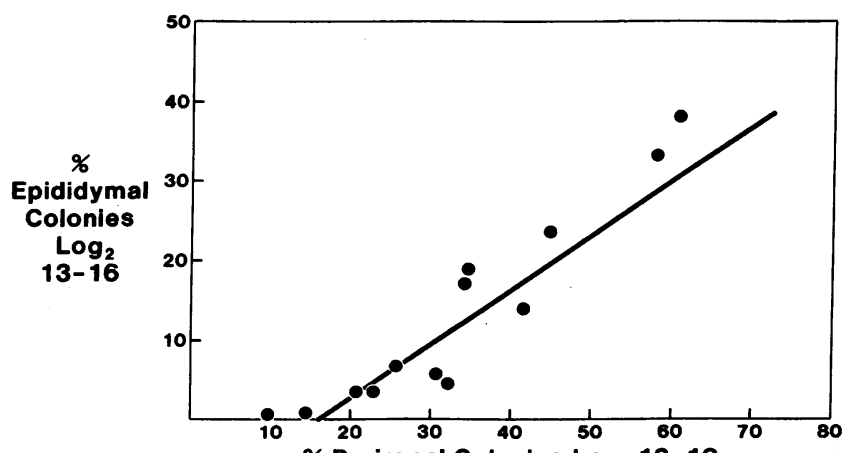

\% Perirenal Colonies $\log _{2}$ 13-16

Figure 2. Relationship between frequencies of rapidly replicating precursor clones in perirenal and epididymal regions. Each point represents the frequencies of colonies of size $\log _{2} 13$ to 16 in perirenal and epididymal precursor populations derived from a single $170-\mathrm{g}$ rat. The perirenal and epididymal precursors of each animal were cultured simultaneously. The regression line was constructed using the method of least squares (correlation coefficient $r=0.941$ ). 
Table III. Effect of Caloric Restriction on Colony Size Distribution

\begin{tabular}{|c|c|c|c|c|c|c|c|c|}
\hline \multirow[b]{3}{*}{ Days } & \multicolumn{4}{|c|}{ Normal ration } & \multicolumn{4}{|c|}{$50 \%$ ration } \\
\hline & \multicolumn{2}{|c|}{ Perirenal } & \multicolumn{2}{|c|}{ Epididymal } & \multicolumn{2}{|c|}{ Perirenal } & \multicolumn{2}{|c|}{ Epididymal } \\
\hline & 0 & 21 & 0 & 21 & 0 & 21 & 0 & 21 \\
\hline Rat wt $g$ & $176 \pm 2$ & $310 \pm 11$ & $172 \pm 1$ & $313 \pm 10$ & $173 \pm 2$ & $179 \pm 3$ & $169 \pm 2$ & $184 \pm 4$ \\
\hline Pad wt $g$ & $128 \pm 23$ & $504 \pm 64$ & $234 \pm 13$ & $880 \pm 68$ & $93 \pm 10$ & $80 \pm 10$ & $205 \pm 17$ & $190 \pm 20$ \\
\hline Colony size & \multicolumn{8}{|c|}{ Percent distribution of colony size } \\
\hline $0-9$ & $43 \pm 3$ & $47 \pm 3$ & $57 \pm 4$ & $68 \pm 5$ & $63 \pm 6$ & $62 \pm 4$ & $76 \pm 5$ & $75 \pm 8$ \\
\hline $10-12$ & $28 \pm 2$ & $28 \pm 2$ & $37 \pm 3$ & $28 \pm 4$ & $21 \pm 3$ & $24 \pm 3$ & $22 \pm 4$ & $22 \pm 8$ \\
\hline $13-16$ & $24 \pm 2$ & $25 \pm 3$ & $6 \pm 1$ & $4 \pm 1$ & $16 \pm 3$ & $14 \pm 2$ & $2 \pm 1$ & $3 \pm 2$ \\
\hline
\end{tabular}

In the normal ration experiment there were 9 and 8 animals in the perirenal and epididymal groups, respectively. In the $50 \%$ ration experiment these numbers were 6 and 6 . Means and standard errors are shown.

Effect of animal growth on clonal composition. In searching for general factors other than nutrition that might influence the clonal composition of precursor populations, we next examined the effects of animal growth. While our previous studies had demonstrated that growth of rats produced a significant increase in the doubling time of populations of adipocyte precursors (10), they did not indicate whether growth affected many or specific clones within the population. To explore this issue, perirenal fat was obtained from three groups of animals weighing $64-72,155-171$, and $427-588 \mathrm{~g}$. These weight ranges corresponded approximately to 3,7 , and $15 \mathrm{wk}$ of age, respectively. Table IV sets out the pooled data for perirenal precursors and also documents the behavior of the most extensively replicating clones, those which produced colonies of size $\log _{2} 16$.

From the pooled data it is clear that growth did not result in a large scale redistribution of the frequencies of the various clones that made up the precursor populations. However, it is also evident that growth did result in a reduction in the frequency of the most extensively replicating clones. Looking at the data in another way, while $63 \%$ of animals of size 64 to $72 \mathrm{~g}$ had at least one perirenal colony of size $\log _{2} 16$, none of the animals of weight 427 to $588 \mathrm{~g}$ produced colonies of this size.

Table IV. Effect of Growth and Age on Perirenal Colony Size Distribution

\begin{tabular}{lccc}
$\begin{array}{l}\text { Rat wt }(g) \\
\text { No. }\end{array}$ & $\begin{array}{c}64-72 \\
(8)\end{array}$ & $\begin{array}{c}155-171 \\
(14)\end{array}$ & $\begin{array}{c}427-588 \\
(10)\end{array}$ \\
Colony size & \multicolumn{3}{c}{$\begin{array}{c}\text { Percent distribution of colony size } \\
\text { Log cell No. }\end{array}$} \\
$0-9$ & $51 \pm 4$ & $49 \pm 3$ & $50 \pm 4$ \\
$10-12$ & $26 \pm 2$ & $27 \pm 2$ & $30 \pm 2$ \\
$13-16$ & $23 \pm 3$ & $24 \pm 4$ & $20 \pm 3$ \\
16 & $0.4 \pm 0.1$ & $0.2 \pm 0.1$ & 0 \\
\hline
\end{tabular}

Increasing weight (and age) was associated with a decreased proportion of large $\left(\log _{2} 16\right)$ colonies $(P<0.05$ by ANOVA). Means and standard errors are shown.
Because of the impact the presence of these extensively replicating clones would have on the doubling times of populations of precursors, it is evident that the progressive reduction in the frequency of these clones with growth was, in fact, responsible for the increase in doubling times previously noted when precursor populations were studied (10).

Relationship of clonal composition to growth of adipose tissue. The content of extensively replicating clones within a precursor population might be a very important determinant of the capacity of the population to support growth of the parent depot. This possible relationship was explored in the next experiments.

In these studies using rats of initial weight $160-210 \mathrm{~g}$, single perirenal or epididymal pads were removed, each from a separate rat, at 0 time and the other pad excised after $70 \mathrm{~d}$ of normal growth. Colony size distribution was measured at 0 time and the number of mature fat cells at both 0 and $70 \mathrm{~d}$; the increment in mature fat cell number over the 70-d interval was then calculated. To use this experimental approach, it was necessary to establish that at one time and in one region not only was clonal composition identical bilaterally (Table I), but also that the number of mature fat cells was the same on both sides. This proposition was tested in two animals; one experiment is shown in Table $\mathrm{V}$. In both regions right and left pads were very similar in fat pad weight, fat cell number, and fat cell size.

Fig. 3 sets out the relationship between the content of extensively replicating clones at 0 time and the subsequent increase in fat cell number during $70 \mathrm{~d}$ of normal feeding. The frequency of colonies of size $\log _{2} 13$ to 16 was used as an index of the frequency of extensively replicating clones in the precursor populations. As expected, precursors from perirenal tissues had a high proportion of extensively replicating clones. Increments in fat cell number were also higher in perirenal as opposed to epididymal fat. Others have also observed that perirenal tissue has a greater capacity for hyperplasia $(1,9,15)$. When taken together, the data from perirenal and epididymal precursors revealed a relationship between content of extensively replicating clones and production of mature fat cells; however within a region this relationship was variable. In particular, in perirenal tissue, marked variation among animals in clonal composition was not always associated with congruent 
Table V. Number and Size of Mature Adipocytes in Right and Left Perirenal and Epididymal Depots

\begin{tabular}{lcccccc}
\hline & \multicolumn{2}{c}{ Perirenal } & & \multicolumn{2}{c}{ Epididymal } \\
\cline { 2 - 3 } \cline { 6 - 7 } & Rt & Lt & & Rt & Lt \\
\hline Pad weight $(m g)$ & 241 & 274 & & 332 & 313 \\
No. adipocytes $\left(\times 10^{5}\right)$ & 27.4 & 27.3 & & 28.8 & 26.5 \\
Adipocyte size $($ ng lipid $)$ & 69.4 & 73.7 & & 90.5 & 83.3 \\
& & & & & &
\end{tabular}

Right and left perirenal and epididymal pads were removed simultaneously from a $210-\mathrm{g}$ rat.

alterations in fat cell number. Hence, while these data support a role for clonal composition in determining depot growth through hyperplasia, obviously the impact of clonal composition on growth must be modified by other factors.

\section{Discussion}

The results of this study have confirmed and extended our earlier observations on the polyclonal nature of rat adipocyte precursor populations. Employing somewhat different techniques than previously and using internally controlled experiments, we have confirmed that adipocyte precursor populations are polyclonal with respect to replication. We have shown that within the same rat, populations derived from anatomically separate regions differ with respect to the frequency of clones of varying replicative capacities.

To extend these studies we have made observations concerning factors that might control clonal composition and we have explored the relationship of clonal composition to the

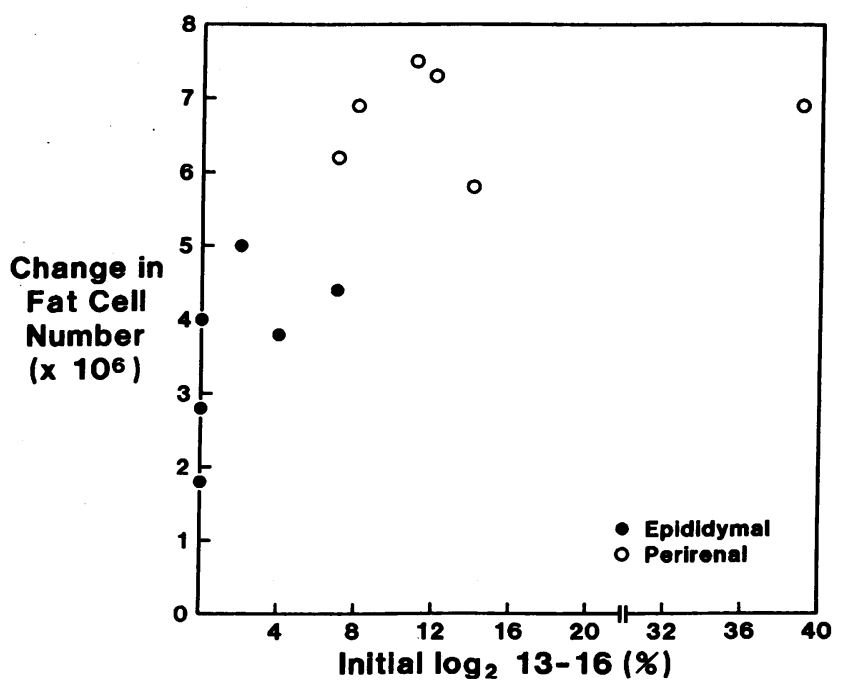

Figure 3. Relation between frequency of rapidly replicating clones and increase in fat cell number with growth. Right or left perirenal or epididymal pads were removed from individual 160-170-g rats at 0 time. The animals were fed a normal ration for $70 \mathrm{~d}$ and the second pad was then removed. An analysis of colony size distribution was made at 0 time and of fat cell number at 0 and $70 \mathrm{~d}$. Colony size distribution at 0 time is plotted against the increment in fat cell number over $70 \mathrm{~d}$. Each point represents a single rat. change in fat cell number that occurs with growth. The overall picture that has emerged from these studies is that the frequency of clones of varying replicative capacities is genetically controlled and is not affected by gross manipulations of food intake. This frequency is modified by growth, at least with respect to the presence of the most extensively replicating clones. It is also evident that there is a general relationship between the clonal composition of the adipocyte precursor population of a depot and the growth of this depot through hyperplasia.

The finding that most strongly suggests genetic control of clonal composition is that of bilateral identity of colony size distribution in paired depots derived from the same anatomic region of one animal. It is very difficult to explain this observation without invoking factors that derive from the common embryological origin of paired depots. Genetic influences could be exerted through the production of enzymes or other intracellular regulators of cell division, or possibly through precursor production of growth factors that could act in an autocrine or paracrine fashion (16). It is tempting to postulate a cause and effect relationship between bilateral identity of clonal composition and bilateral identity of fat cell number (Table V).

The observation that there is extensive interanimal variation in clonal composition and that the direction of interanimal differences is the same in the two depots studied, suggests that within an animal there is coordinate regulation of clonal composition of at least two depots and that this regulation varies among animals. In searching for regulatory influences that could exert effects in multiple depots it was reasonable to explore the effects on clonal composition of $(a)$ undernutrition, a situation known to alter new fat cell formation, $(b)$ animal growth that results in a prolongation of doubling times of precursor populations. The only circumstance that produced a lasting effect on the frequency of clones of varying replicative capacities was normal growth, which led to a specific deletion of the most extensively replicating clones. This phenomenon may have resulted from the development of gene products that appear with aging (17). Alternatively, as has been previously hypothesized (10), over time the most extensively replicating clones on differentiation might have matured, left the precursor pool and moved into the mature fat cell compartment. Because of the known effects of pituitary and other hormones on adipocyte precursor replication both in vivo (4) and in cell culture (5), it will be of interest to explore the possibility that the effects of growth on clonal composition is hormonally mediated.

The present study also suggests that a relationship exists between clonal composition and adipose depot growth. Differences between perirenal and epididymal depots in content of extensively replicating clones were associated with differences between these depots in the extent to which fat cell number increased with growth. Perirenal depots, which contained more extensively replicating precursors underwent a greater increase in fat cell number over time. However, while the relationship between clonal composition and depot growth was apparent when data from the two depots were combined, the relationship was less evident when the individual data applicable to one depot were examined. In considering other factors that might influence development of mature fat cells it is reasonable to focus on total numbers of precursors in a depot, not just proportions of various clones, and on environ- 
mental factors that could influence maturation of fat cell precursors (e.g., nutrition, energy balance, hormone action). Only under circumstances in which two depots contain the same numbers of precursors and the same proportions of various precursor clones and in which the depots are exposed to the same environmental influences, would it be expected that the depots would develop similar numbers of fat cells. Presumably, this unique situation applies to right and left depots of a single anatomic region. In all other circumstances inter-regional or interanimal variation in precursor number, clonal composition or environmental effects could lead to the production of variable numbers of fat cells. Hence it is possible that clonal composition determines the ultimate capacity of a depot to grow through hyperplasia and that other factors, such as environmental influences, determine the extent to which this capacity is expressed. This hypothesis is consistent with the observation that there is a limit to epididymal depot growth through hyperplasia while perirenal tissue displays no such constraint (1).

It will be of considerable interest to explore the molecular basis of the differences between individual precursors in replicative capacities. It will also be of interest to determine whether differences between individual precursors are the cause of the differences in cell size and metabolic behavior that have been shown to exist among the mature fat cells derived from an adipose depot $(12,18)$. As a working hypothesis it is proposed that the mosaic nature of the mature fat cell fraction of a fat depot is derived from the polyclonal nature of the adipocyte precursors that have given rise to the mature adipocytes.

\section{Acknowledgments}

The authors are grateful to $\mathrm{S}$. Kindler and W. Gillon for valuable technical assistance and to N. Rankin for expert secretarial help.

Supported by Medical Research Council of Canada grant 7679 and the Queen Elizabeth Hospital Foundation. Dr. Wang was a Fellow of the Medical Research Council of Canada.

\section{References}

1. Bertrand, H. A., and E. J. Masoro. 1978. Increasing adipocyte number as the basis for perirenal depot growth in adult rats. Science (Wash. DC). 201:1234-1235.
2. Knittle, J. C., K. Timmers, F. Guisberg-Fellner, R. E. Brown, and P. P. Katz. 1979. The growth of adipose tissue in children and adolescents. Cross-sectional and longitudinal studies of adipose cell number and size. J. Clin. Invest. 63:239-246.

3. Hirsch, J., and P. W. Han. 1969. Cellularity of rat adipose tissue. Effects of growth, starvation and obesity. J. Lipid Res. 10:77-82.

4. Hollenberg, C. H., and A. Vost. 1968. Regulation of DNA synthesis in fat cells and stromal elements from rat adipose tissue. J. Clin. Invest. 47:2485-2498.

5. Roncari, D. A. K. 1981. Hormonal influences on the replication and maturation of adipocyte precursors. Int. J. Obes. 5:547-552.

6. Hirsch, J., and B. Batchelor. 1976. Adipose tissue cellularity in human obesity. Clin. Endocrinol. Metab. 5:299-311.

7. Roncari, D. A. K., D. C. W. Lau, and S. Kindler. 1981. Exaggerated replication in culture of adipocyte precursors from massively obese persons. Metab. Clin. Exp. 30:425-427.

8. Faust, I. M., P. R. Johnson, and J. Hirsch. 1977. Adipose tissue regeneration following lipectomy. Science (Wash. DC). 197:391-393.

9. Faust, I. M., P. R. Johnson, J. S. Stern, and J. Hirsch. 1978. Diet-induced adipocyte number increase in adult rats. A new model of obesity. Am. J. Physiol. 235:E279-E289.

10. Djian, P., D. A. K. Roncari, and C. H. Hollenberg. 1983. Influence of anatomic site and age on the replication and differentiation of rat adipocyte precursors in culture. J. Clin. Invest. 72:12001208.

11. Djian, P., D. A. K. Roncari, and C. H. Hollenberg. 1985. Adipocyte precursor clones vary in capacity for differentiation. Metab. Clin. Exp. 34:880-883.

12. Di Girolamo, M., and S. Mendlinger. 1971. Role of fat cell size and number in enlargement of epididymal fat pads in three species. Am. J. Physiol. 221:859-864.

13. Folch, J., M. Lees, and G. H. Sloan Stanley. 1957. A simple method for the isolation and purification of total lipids from animal tissues. J. Biol. Chem. 226:497-509.

14. Keppel, G. 1973. Design and Analysis: A Researcher's Handbook. Prentice-Hall Inc., NJ.

15. Klyde, B. J., and J. Hirsch. 1979. Isotopic labelling of DNA in rat adipose tissue. Evidence for proliferating cells associated with mature adipocytes. J. Lipid Res. 20:691-704.

16. Lau, D. C. W., D. A. K. Roncari, and C. H. Hollenberg. 1987. Release of mitogenic factors by cultured preadipocytes from massively obese human subjects. J. Clin. Invest. 79:632-636.

17. Lumpkin, C. K., J. K. McClung, O. P. Pereira-Smith, and J. R. Smith. 1986. Existence of high abundance of antiproliferative mRNA's in senescent human diploid fibroblasts. Science (Wash. DC). 232:393-395.

18. Cushman, S. W., and L. B. Salans. 1978. Determination of adipose cell size and number in suspensions of isolated rat and human adipose cells. J. Lipid Res. 19:269-273. 